\title{
Suitable Laboratory Ranges of Confinement Stresses for Performance Testing of Asphalt Concrete
}

\author{
Lee P. Leon, $\mathrm{MSc}^{1}$, Derek Gay, $\mathrm{PhD}^{1}$ \\ ${ }^{1}$ University of The West Indies, Trinidad \& Tobago, lee.leon@sta.uwi.edu, derek.gay@sta.uwi.edu
}

\begin{abstract}
Flexible pavement distress prediction is largely based on laboratory and numerical simulation. The traditional triaxial laboratory performance testing of asphalt concrete has been carried out at various confining (radial) stress states, however they vary significantly in literature and some did not appear to relate to an appropriate in-situ field condition. The behavior of a flexible pavement structure is modelled in ABAQUS using axisymmetric finite element analysis. The interface between wheel and pavement does not significantly affect vertical stress states with depth, however the horizontal stress states decreases. The proposed confining stress value for performance testing of asphalt concrete should be between ranges of $30 \%$ to $40 \%$ of the (vertical stress) applied axial loading.
\end{abstract}

Keywords-- Asphalt Concrete, Confining Stresses, ABAQUS, Radial Stresses

\section{INTRODUCTION}

Road pavements are subjected to loading by heavy and most times overloaded vehicles. This causes stress and strain distribution over layers of the pavement and the subgrade. Pavement researchers use materials and environmental data and constitutive theories to simulate and evaluate field performance of asphalt pavements. An appreciation for the distribution of stress and strain can help to better understand the behavior of the pavement during the service time. For this purpose, the mechanical characteristics like elastic modulus, wheel loading and other laboratory test and simulation parameters have to be known.

The structural behavior of a pavement is ascertained by its response to applied stresses. Stresses and the resultant pavement response are the combined result of loading, environment, subgrade and pavement material characteristics. The vertical stress dissipates rather slowly with depth however for the horizontal stress behavior at the bottom of the layer, it experiences compression near layer interface, which then gradually decreases to zero with increasing depth. Directly under the wheel load the pavement is under compression while most of the surrounding pavement is under very little stress.

Asphalt concrete (AC) is heterogeneous with timehistory-dependent characteristics. Prediction of the behavior of asphalt concrete under realistic repetitive loading is essential to the design and analysis of asphalt concrete pavement. Passing wheel on flexible pavements exhibits a reaction as shown in Fig. 1. Ref. [2] stated that wheel loading leads to stresses and strains within the pavement structure.

Digital Object Identifier (DOI): http://dx.doi.org/10.18687/LACCEI2018.1.1.243 ISBN: 978-0-9993443-1-6

ISSN: $2414-6390$

$16^{\text {th }}$ LACCEI International Multi-Conference for Engineering, Education, and Technology: "Innovation in Education and Inclusion", 18-20 July 2018, Lima, Peru.
The axial deformation lags the axial stresses due to the viscoelastic behavior of bituminous bound materials. Points within the structure are confined in the radial direction, however no or very limited radial deformation occurs. Furthermore, radial stresses result from this confinement, which lag the axial stresses as well. For cyclic loading these lags can be described as phase angles which are specific viscoelastic material parameters of bituminous mixes.

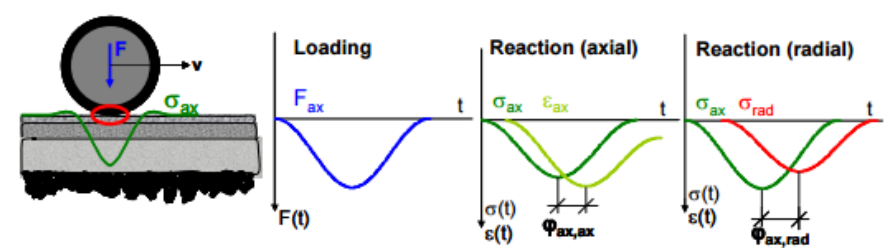

Fig. 1 Reaction of a flexible pavement structure due to loading [2]

The laboratory tests developed are used to simulate the best realistic response of the pavement structure or layer to the applied traffic loading. The stresses that occur in a flexible pavement under load are quite complex. An understanding of the interaction of load and materials as well as the influence of temperature, needs to be understood in order to interpret the behavior of in-situ conditions in the laboratory or through numerical techniques. The tri-axial test is one of the most versatile and widely performed geotechnical laboratory tests. Continuous cycles of loadings at a constant strain or stress amplitude, generally applied in laboratory tests, do not realistically simulate the compound-loading conditions to which a paving material is subjected under actual traffic conditions.

Although many laboratory experiments have been conducted to simulate a real vehicle-to-pavement interaction system under the experimental conditions such as environment and applied load, there are significant differences in the load systems and the environment conditions between the laboratory experiments and those encountered in real vehicle to road interaction Ref. [4].

Various researchers, as shown in Table I have used cyclic compression test to characterize permanent deformation behavior of asphalt concrete. However, the axial applied stress $\left(\sigma_{z}\right)$ and the confining stress $\left(\sigma_{r}\right)$ varied significantly. The research seeks to explore a suitable range of confining stresses that should be employed in a tri-axial compression test. The range of values should be an appropriate representation of typical in-situ radial stress states within a pavement structure. 
TABLE I

Summary of Documented Test PARAMETERS When Using CyCliC COMPRESSION TEST

\begin{tabular}{|l|c|c|c|}
\hline Researcher(s) & $\begin{array}{c}\text { Axial Stress } \\
\left(\sigma_{\mathrm{z}}\right)(\mathrm{kPa})\end{array}$ & $\begin{array}{c}\text { Confining } \\
\text { Stress }\left(\sigma_{\mathrm{r}}\right) \\
(\mathrm{kPa})\end{array}$ & $\begin{array}{c}\text { Confining } \\
\text { Stress Ratio } \\
\left(\sigma_{3} / \sigma_{1}\right)(\%)\end{array}$ \\
\hline Ref. [7] & $814-3523$ & $0-400$ & 11 \\
\hline Ref. [3] & 100,200 & 33,67 & 33 \\
\hline Ref. [5] & 448,2246 & 138 & 31,6 \\
\hline Ref. [1] & 483,827 & 138 & 17 \\
\hline Ref. [2] & 300 & 150 & 50 \\
\hline Ref. [6] & 1860 & 100,200 & 5,11 \\
\hline
\end{tabular}

\section{SIMULATION PROCEDURE}

\section{A. Pavement Structure}

The stresses that occur in a flexible pavement under load are quite complex. An understanding of the interaction of load and materials as well as the influence of temperature needs to be understood in order to interpret the behavior of in-situ conditions in the laboratory or through numerical techniques. Fig. 2 below shows the typical schematic of the interaction with the traffic and the pavement structure.

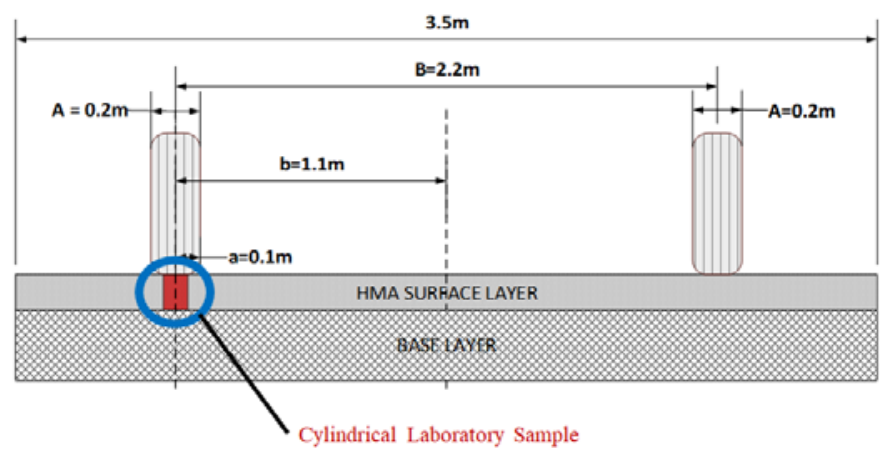

Fig. 2 Wheel loading and laboratory sample within a pavement structure

\section{B. Laboratory Sample and Testing Assumptions}

The traditional laboratory test mentioned previously is used to simulate field conditions that helps pavement designers evaluate the behavior of load, temperature and material interactions. A major influence in laboratory procedure is the influence of sample geometry and suitable representation of vertical and horizontal in-situ stress states. From Fig. 3 the test sample heights are shown and should be representations of layer thickness. The vertical stress $\left(\sigma_{\mathrm{z}}\right)$ and confining (radial) stress $\left(\sigma_{\mathrm{r}}\right)$ are represented by the wheel loading and the stresses induced within the layer respectively.

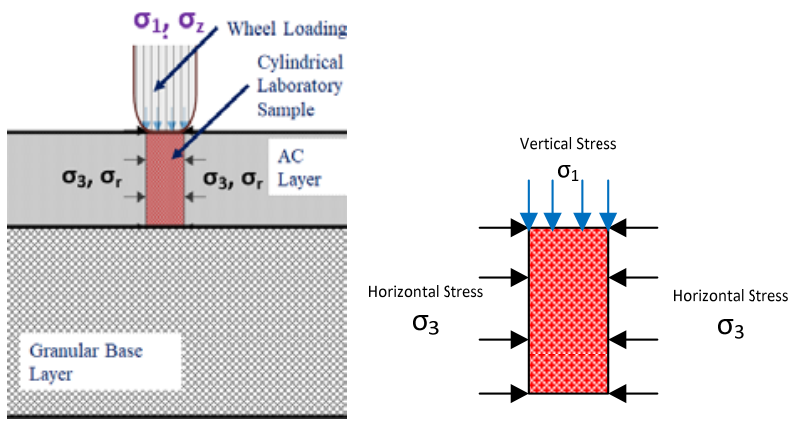

Fig. 3 Laboratory sample and its induced in-situ stresses

\section{Pavement Model Geometry and Assumptions}

In the finite element (FE) static analysis, the layer materials are model using elastic theory and is described in (1) and (2) by the cylindrical form of the elastic stress strain relationship for materials. Linear elasticity is the simplest form of elasticity available in ABAQUS. A linear elastic material model is valid for small elastic strains (normally less than 5\%); can be isotropic, orthotropic, or fully anisotropic; and can have properties that depend on temperature and/or other field variables.

$\varepsilon_{r}=\frac{1}{E}\left[\sigma_{r}-v\left(\sigma_{z}\right)\right]$

$\varepsilon_{z}=\frac{1}{E}\left[\sigma_{z}-v\left(\sigma_{r}\right)\right]$

Where: $\sigma_{\mathrm{r}}=$ radial stress

$\sigma_{\mathrm{z}}=$ vertical stress

$\varepsilon_{\mathrm{r}}=$ radial strain

$\varepsilon_{\mathrm{z}}=$ vertical strain

$\mathrm{E}=$ elastic modulus of the materials

$v=$ Poisson ratio

The pavement section is simulated by using FE axisymmetric geometry. The model consists of an asphalt course layer with thicknesses of $50 \mathrm{~mm}, 100 \mathrm{~mm}, 150 \mathrm{~mm}$, $200 \mathrm{~mm}$ and a granular course layer with a thickness of $300 \mathrm{~mm}$. The width of the model as shown in Fig. 4 was selected to represent the distance from the center of tire to the center of the vehicle. The model evaluates two tire and surface layer interface; (1) Boundary condition 1 represents no friction and, (2) Boundary condition 2 the nodes are restricted horizontally, which simulates a degree of friction at the interface. The loading applied as an axial stress $\left(\sigma_{z}\right)$ of 200 $\mathrm{kPa}$ and $800 \mathrm{kPa}$. The analysis was done assuming static loading condition. 


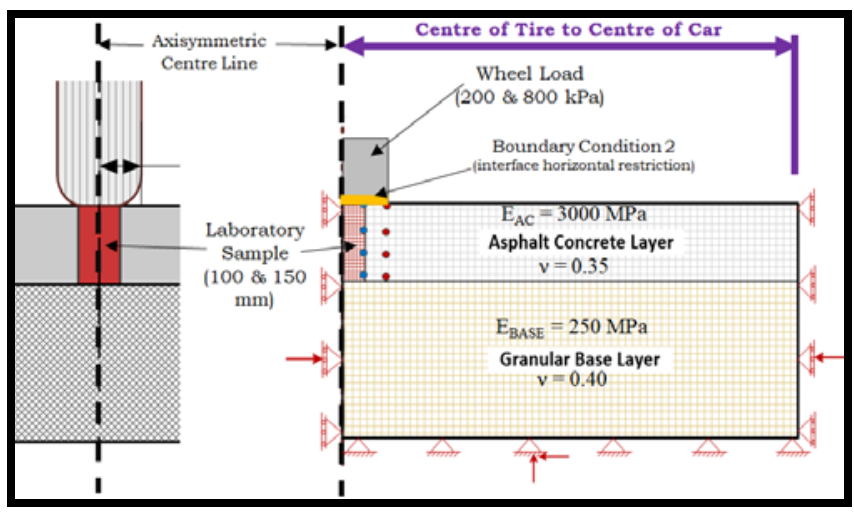

Fig. 4 Sample Geometries of Proposed ABAQUS Simulation

\section{RESULTS AND ANALYSIS}

\section{A. Vertical Stresses}

The highest vertical stresses are concentrated at the top of the AC layer and dissipates with depth. This behavior holds true to any combination of surface layer thickness, wheel loading, and tire-surface interface boundary conditions. There is discontinuity of the stress distribution between the surface and base layer interface as shown in Fig. 5. This behavior is due to the great difference in the layer elastic material properties as defined in (1) and Fig. 4.

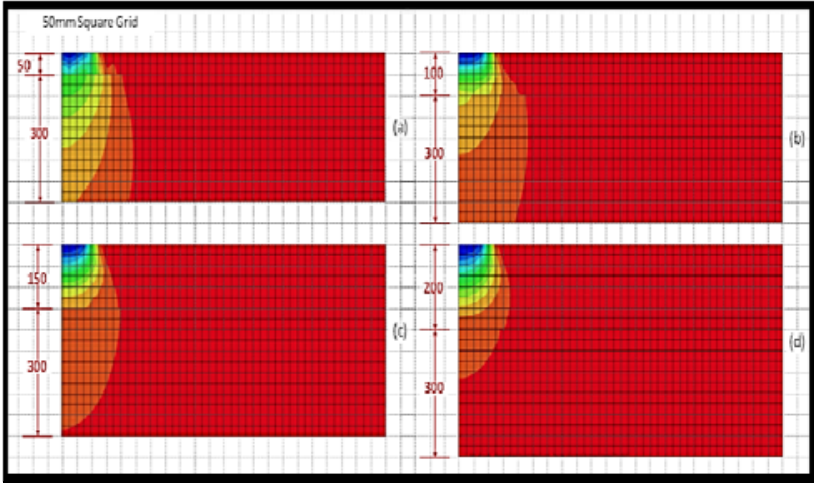

Fig. 5 Vertical Stress Behavior in Entire Pavement Structure due to Static Loading

In Fig. 6 and Fig. 7 the vertical stress values at the top of AC layer are approximately equal to $0.9 \sigma_{z}$ (sample edge) and $0.5 \sigma_{z}$ (tire edge) at any given pavement thickness and tiresurface interface boundary condition. At the bottom of the asphalt concrete layer, the representative laboratory sample edges stresses values are approximately $0.7 \sigma_{\mathrm{z}}(50 \mathrm{~mm}), 0.3 \sigma_{\mathrm{z}}$ $(100 \mathrm{~mm}), 0.2 \sigma_{\mathrm{z}}(150 \mathrm{~mm})$ and $0.12 \sigma_{\mathrm{z}}(200 \mathrm{~mm})$, for both tiresurface interface boundary conditions. The behavior of the stress is similar to typical theoretical vertical stress distributions mentioned in the introduction.

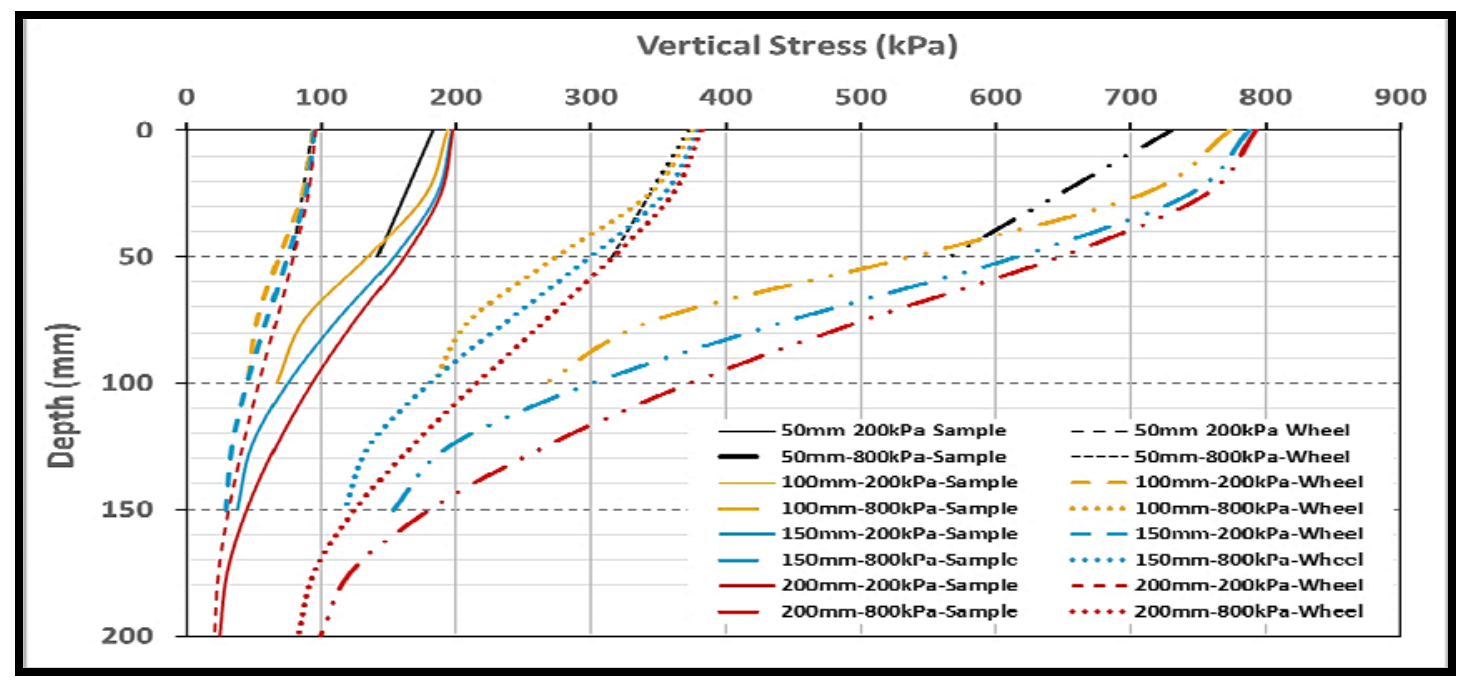

Fig. 6 Vertical Stress Distribution in AC Layer - Boundary Condition 1

16 $^{\text {th }}$ LACCEI International Multi-Conference for Engineering, Education, and Technology: "Innovation in Education and Inclusion", 18-20 July 2018, Lima, Peru. 


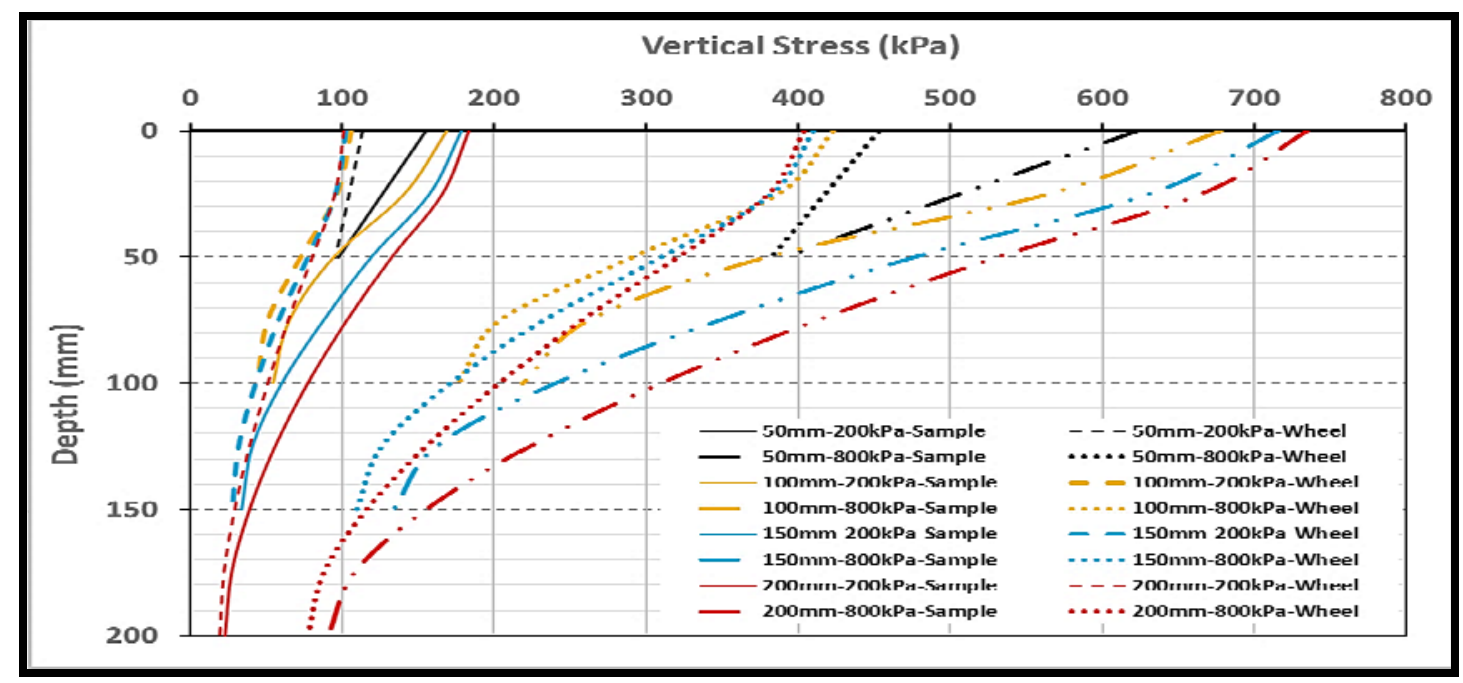

Fig. 7 Vertical Stress Distribution in AC Layer - Boundary Condition 2

\section{B. Horizontal (Radial) Stresses}

The highest radial stresses as shown in Fig. 8, 9 and Fig. 10 are concentrated at the top and bottom of the Asphalt Concrete layer, however the radial stress distribution within the layer experiences both compression and tension stresses.

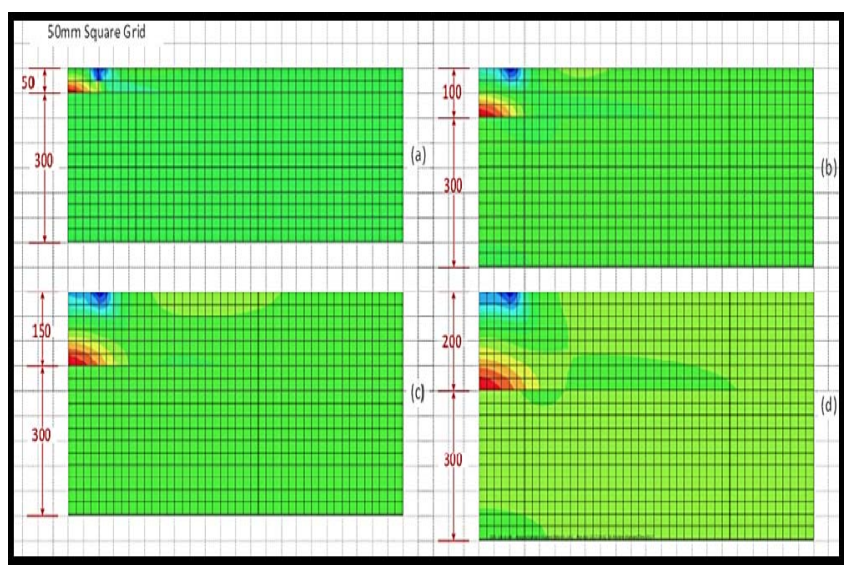

Fig. 8 Confining (Radial) Stress Behavior in Pavement Structure due to Static Loading

The radial (confining) stress values at the top of AC layer are approximately equal to $1.5 \sigma_{\mathrm{z}}(50 \mathrm{~mm}), 1.25 \sigma_{\mathrm{z}}(100 \mathrm{~mm})$, $1.0 \sigma_{\mathrm{z}}(150 \mathrm{~mm})$ and $0.9 \sigma_{\mathrm{z}}(200 \mathrm{~mm})$; sample edge, and $0.5 \sigma_{\mathrm{z}}$ $(50 \mathrm{~mm}), 0.7 \sigma_{\mathrm{z}}(100 \mathrm{~mm}), 0.6 \sigma_{\mathrm{z}}(150 \mathrm{~mm})$ and $0.5 \sigma_{\mathrm{z}}(200$ $\mathrm{mm}$ ); tire edge. However, as shown in Fig. 10, when boundary condition 2 is applied the stress values $0.03 \sigma_{z}(50 \mathrm{~mm}), 0.4 \sigma_{z}$ $(100 \mathrm{~mm}), 0.4 \sigma_{\mathrm{z}}(150 \mathrm{~mm})$ and $0.4 \sigma_{\mathrm{z}}(200 \mathrm{~mm})$; sample edge, and $1.0 \sigma_{\mathrm{z}}(50 \mathrm{~mm}), 0.9 \sigma_{\mathrm{z}}(100 \mathrm{~mm}), 0.7 \sigma_{\mathrm{z}}(150 \mathrm{~mm})$ and $0.6 \sigma_{\mathrm{z}}$ $(200 \mathrm{~mm})$; tire edge.

At the bottom of the asphalt concrete layer, the representative laboratory samples edge stress values are approximately $0.8 \sigma_{\mathrm{z}}(50 \mathrm{~mm}), 0.8 \sigma_{\mathrm{z}}(100 \mathrm{~mm}), 0.6 \sigma_{\mathrm{z}}(150$ $\mathrm{mm})$ and $0.4 \sigma_{z}(200 \mathrm{~mm})$. However, when interface boundary condition 2 is applied, the stress values are within approximate ranges of $0.9 \sigma_{z}(50 \mathrm{~mm}), 0.7 \sigma_{z}(100 \mathrm{~mm}), 0.5 \sigma_{z}$ $(150 \mathrm{~mm})$ and $0.4 \sigma_{z}(200 \mathrm{~mm})$ at the sample edge.

The radial compressive stress distribution for $100 \mathrm{~mm}, 150 \mathrm{~mm}$ and $200 \mathrm{~mm}$ AC layer are distributed to an approximate depth of $60 \%$ of the height below the surface for both 200 and $800 \mathrm{kPa}$ tire loading. This location also applies to any tire-interface conditions and asphalt concrete layer greater than $100 \mathrm{~mm}$ thick. The $50 \mathrm{~mm}$ layer however has a different stress distribution pattern.

There was a significant difference in the stresses experienced at the top of the sample because of the horizontal node restriction (friction assumption). At the samples region, the stresses in interface condition 2 were approximately $60 \%$ less than that of boundary condition 1 . However, the values of stresses at the bottom of the layer at the edge of the patch (tire) load were similar for any tire-pavement interface. 


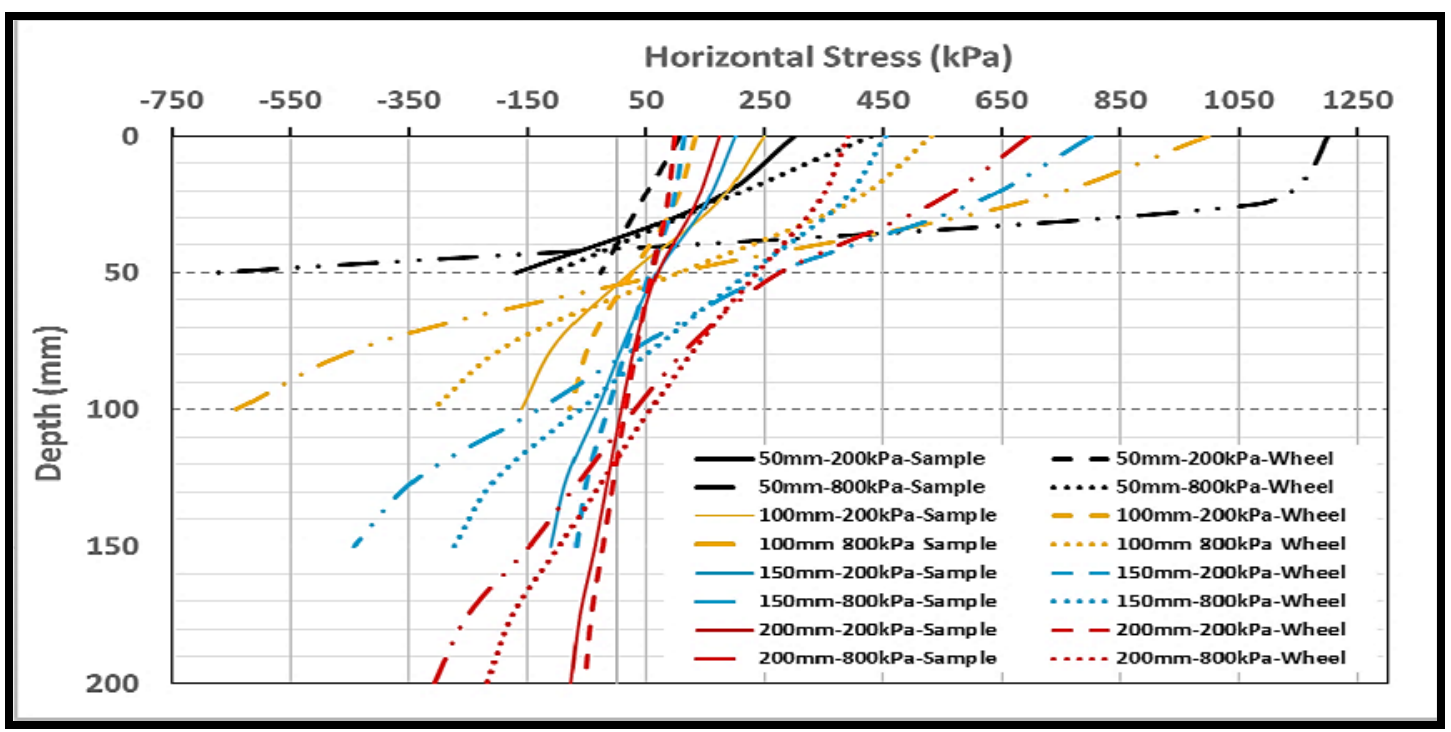

Fig. 9 Radial Stress Distribution in AC Layer - Boundary Condition 1

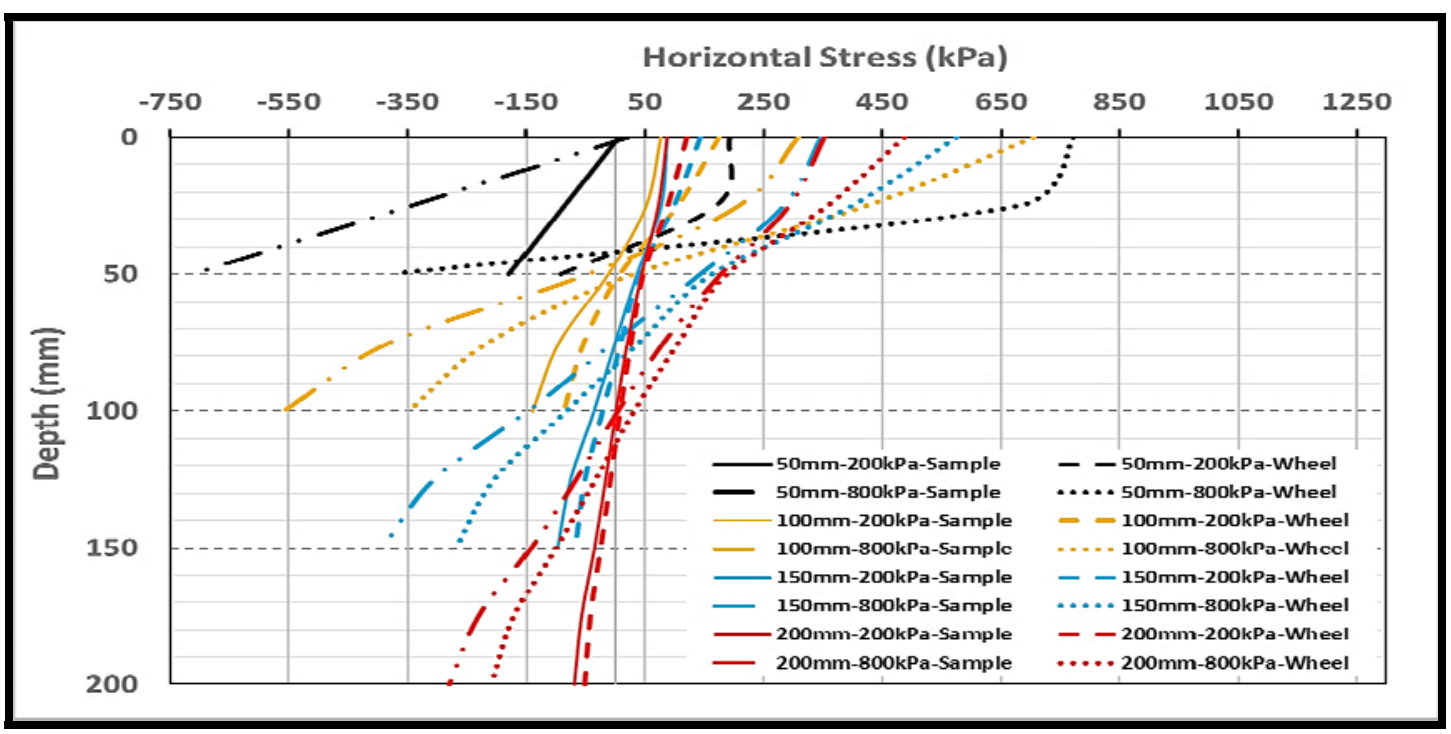

Fig. 10 Radial Stress Distribution in AC Layer - Boundary Condition 2

\section{FE Results Validation}

The ABAQUS results were validated using a pavement structure design program known as FPS21 developed by Texas A\&M University's Texas Transportation Institute for the Texas Department of Transportation (TxDOT). The Flexible Pavement System (FPS) is a mechanistic-empirically (M-E) based design software routinely used by the Texas Department of Transportation (TxDOT)The program accesses the stress-strain analysis of pavement layers such as the bottom of asphalt layer and the top of the base layer. The same pavement geometry (depth) and material properties used in ABAQUS were inputs into FPS21.

Table II and Fig. 11 shows the comparison of the two set of output. The range of values predicted by boundary condition 2 shows a closer resemblance to the range of values of axial stresses to radial stress used in previous research as presented in Table I.

Case 1 predicted values has significant differences because the values are much greater than that of Table I. The results of a layer of $50 \mathrm{~mm}$ had great variance in the data when compared with the other thicknesses. This could have been the result of the mesh standard mesh size used to represent all layers.

The range predicted within this report simulation for a suitable confining stress for laboratory test can be approximated to be between $30-40 \%$ of the applied tire load (vertical stress). It can also be concluded that ABAQUS is a suitable FE package that can be used to evaluate the behavior of stresses and strain in the pavement structure.

$1^{\text {th }}$ LACCEI International Multi-Conference for Engineering, Education, and Technology: "Innovation in Education and Inclusion”, 18-20 July 2018, Lima, Peru. 


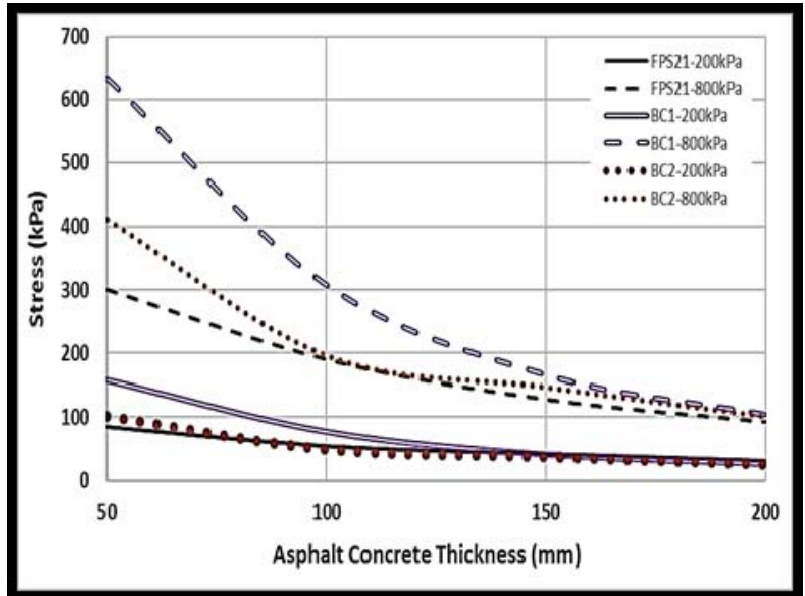

(a)

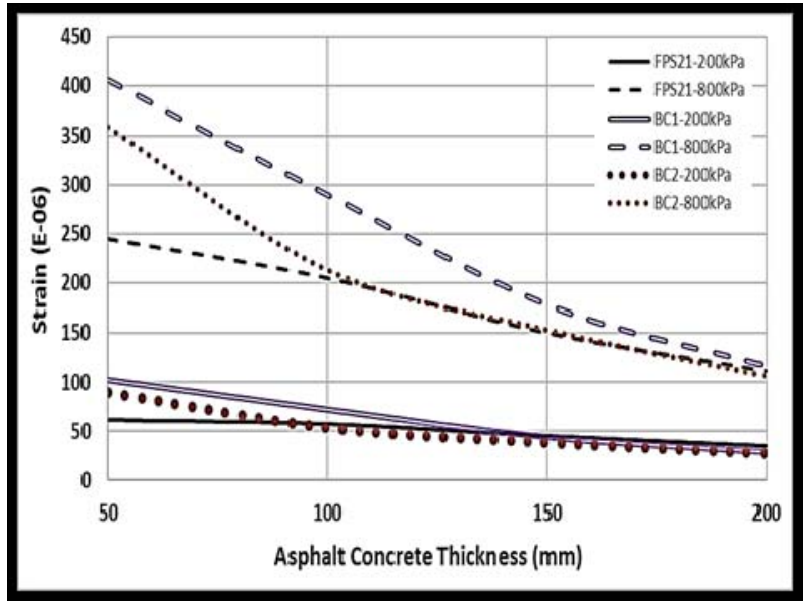

(b)

Fig. 11 Effects of Layer Thickness on (a) Stress and (b) Strain

TABLE II

Summary of Documented TeSt Parameters When USING CyClic COMPRESSION TEST

\begin{tabular}{|c|c|c|c|c|c|c|c|}
\hline $\begin{array}{l}\text { AC Layer } \\
\text { Thickness } \\
\text { (mm) }\end{array}$ & Measured Variables & \multicolumn{2}{|c|}{ FPS 21} & \multicolumn{2}{|c|}{$\begin{array}{c}\text { ABAQUS } \\
\text { Interface Boundary } \\
\text { Condition } 1\end{array}$} & \multicolumn{2}{|c|}{$\begin{array}{c}\text { ABAQUS } \\
\text { Interface Boundary } \\
\text { Condition } 2\end{array}$} \\
\hline \multicolumn{2}{|c|}{ Tire Load (Applied Vertical Stress) } & $200 \mathrm{kPa}$ & $800 \mathrm{kPa}$ & $200 \mathrm{kPa}$ & $800 \mathrm{kPa}$ & $200 \mathrm{kPa}$ & $800 \mathrm{kPa}$ \\
\hline \multirow{4}{*}{50} & \multirow{2}{*}{$\begin{array}{c}\text { Vertical Strain } \\
\text { (microns) }\end{array}$} & 61 & 245 & 102 & 406 & 89 & 359 \\
\hline & & \multicolumn{2}{|c|}{ error \% } & $\underline{67}$ & $\underline{66}$ & $\underline{46}$ & $\underline{47}$ \\
\hline & \multirow{2}{*}{$\begin{array}{c}\text { Vertical Stress } \\
\qquad(\mathrm{kPa})\end{array}$} & 84 & 300 & 158 & 633 & 102 & 411 \\
\hline & & \multicolumn{2}{|c|}{ error $\%$} & $\underline{88}$ & $\underline{111}$ & $\underline{21}$ & $\underline{37}$ \\
\hline \multirow{4}{*}{100} & \multirow{2}{*}{$\begin{array}{c}\text { Vertical Strain } \\
\text { (microns) }\end{array}$} & 57 & 205 & 72 & 290 & 53 & 213 \\
\hline & & \multicolumn{2}{|c|}{ error $\%$} & 26 & 41 & -7 & $\underline{4}$ \\
\hline & \multirow{2}{*}{$\begin{array}{c}\text { Vertical Stress } \\
(\mathrm{kPa})\end{array}$} & 54 & 190 & 77 & 307 & 49 & 196 \\
\hline & & \multicolumn{2}{|c|}{ error $\%$} & $\underline{43}$ & $\underline{62}$ & $\underline{-9}$ & $\underline{3}$ \\
\hline \multirow{4}{*}{150} & \multirow{2}{*}{$\begin{array}{l}\text { Vertical Strain } \\
\text { (microns) }\end{array}$} & 45 & 150 & 44 & 178 & 38 & 153 \\
\hline & & \multicolumn{2}{|c|}{ error \% } & -2 & $\underline{19}$ & -16 & 2 \\
\hline & \multirow{2}{*}{$\begin{array}{c}\text { Vertical Stress } \\
(\mathrm{kPa})\end{array}$} & 42 & 128 & 41 & 165 & 37 & 147 \\
\hline & & \multicolumn{2}{|c|}{ error $\%$} & -2 & 29 & -12 & $\underline{15}$ \\
\hline \multirow{4}{*}{200} & \multirow{2}{*}{$\begin{array}{l}\text { Vertical Strain } \\
\text { (microns) }\end{array}$} & 35 & 111 & 29 & 116 & 27 & 106 \\
\hline & & \multicolumn{2}{|c|}{ error $\%$} & -17 & $\underline{5}$ & -23 & -5 \\
\hline & \multirow{2}{*}{$\begin{array}{c}\text { Vertical Stress } \\
(\mathrm{kPa})\end{array}$} & 31 & 93 & 26 & 103 & 25 & 101 \\
\hline & & \multicolumn{2}{|c|}{ error $\%$} & -16 & $\underline{11}$ & -19 & $\underline{9}$ \\
\hline
\end{tabular}

\section{CONCLUSIONS}

The level of friction (restriction) between tire and pavement interface (surface boundary condition) does not significantly affect vertical stress states, nonetheless the horizontal stress states decrease by $43 \%$ of vertical applied stress (wheel load).

The research also suggested that when the thickness of the asphalt concrete layer increases, the corresponding stresses and strain within the layer decreases.
The neutral axis between the radial tensile and compressive stresses are located $2 / 3$ from the top of the surface. This only applies for thickness of layers greater than $100 \mathrm{~mm}$. At layer thicknesses less than $100 \mathrm{~mm}$ only compressive stresses are recorded. The location of the neutral axis is vital as it can indicate to pavement designers the possible depth range engineering applications (geo-grids) to improve the tensile capabilities of an asphaltic layer.

$16^{\text {th }}$ LACCEI International Multi-Conference for Engineering, Education, and Technology: "Innovation in Education and Inclusion", 18-20 July 2018, Lima, Peru. 
FE simulation indicate that confining stress values between ranges of $30 \%-45 \%$ of the applied axial test loading is a suitable value for performance testing.

\section{REFERENCES}

[1] Brown, Ray E., Kandhal, Prithvi S., and Zhang, Jingna. 2001. "Performance Testing for Hot Mix Asphalt." National Center of Asphalt Technology (NCAT), NCAT Report 01-05

[2] Hofko, Bernhard. 2015. "Addressing The Permanent Deformation Behaviour of Hot Mix Asphalt by Triaxial Cyclic Compression Testing with Cyclic Confining Pressure.” Journal of Traffic and Transportation Engineering (English Edition), 2015, 2(1): pp. 17-29

[3] Kim, J.R., Drescher A., and Newcomb E. 1997. "Rate Sensitivity of Asphalt Concrete in Triaxial Compression." Journal of Materials in Civil Engineering, 1997,9(2): pp. 76-84

[4] Lian-Sheng, G., Han-cheng, D., and Jia-qi, C. 2017. "Research on Predicting the Rutting of Asphalt Pavement Based on a Simplified Burgers Creep Model." Mathematical Problems in Engineering, 2017.

[5] Ramssamooj, D.V., Ramadan, J., and Lin, G.S. 1998. "Model Prediction of Rutting in Asphalt Concrete." Journal of Transportation Engineering, 1998, 124(5): pp. 448-456

[6] Roy, Neethu. Veeraragavan A., and Krishnan J Murali. 2015. "Influence of Confinement Pressure and Air Voids On the Repeated Creep and Recovery of Asphalt Concrete Mixtures." International Journal of Pavement Engineering, Vol. 17, No. 2, 133-147, http://dx.doi.org/10.1080/10298436.2014.925622

[7] Tan, Siew-Ann., Low, Boon-Howe., and Fwa Tien-Fang. 1994. "Behaviour of Asphalt Concrete Mixtures in Triaxial Compression." Journal of Testing and Evaluation, JTEVA. Vol. 22, pp. 195-203

16 $^{\text {th }}$ LACCEI International Multi-Conference for Engineering, Education, and Technology: "Innovation in Education and Inclusion", 18-20 July 2018, Lima, Peru. 